\title{
Tryptophan metabolism in depression
}

\author{
G. CURZON AND P. K. BRIDGES
}

From the Department of Chemical Pathology, Institute of Neurology, Queen Square, London, and from the Department of Psychological Medicine, The Royal Free Hospital, London

SUMMARY Psychiatric patients suffering from endogenous depression and a control group without endogenous depression were given oral loads of L-tryptophan and urinary excretion determined of the tryptophan metabolites on the pyrrolase pathway: kynurenine, 3-hydroxykynurenine, and 3-hydroxyanthranilic acid. Female endogenously depressed subjects excreted significantly more kynurenine and 3-hydroxykynurenine but not the subsequent metabolite 3-hydroxyanthranilic acid than did female control subjects. Variability of excretion of kynurenine and 3-hydroxykynurenine at different times by the same subject was much greater in the endogenously depressed than in the control group. There was no consistent temporal relationship between excretion of metabolites and severity of the depressive illness. The possible significance of the findings in relation to defective tryptophan metabolism in the brain in endogenous depression is commented upon.

The considerable efficacy of physical treatments in patients with affective illnesses has encouraged research into the implied physical abnormalities present. A relatively specific indication of the presence of a biochemical disturbance is provided by the therapeutic effectiveness of monoamine oxidase inhibitor (MAOI) and tricyclic antidepressants, which influence monoamine metabolism. The extent to which amines derived from tryptophan, such as 5-hydroxytryptamine (5HT), and those derived from tyrosine, such as the catecholamines, play a part in the regulation of mood has been the subject of much controversy and has been discussed by Schildkraut (1965) and by Brodie and Reid (1968).

There is considerable evidence that tryptophan metabolism is disturbed in affective illnesses. Thus the therapeutic activity of MAOI compounds was found by Coppen, Shaw, Herzberg, and Maggs (1967) to be enhanced by oral tryptophan, suggesting that depression may be associated with insufficient cerebral 5HT. In addition, depressed subjects responding to iproniazid were found by Pare and Sandler (1959) and Van Praag and Leijnse (1963), but not by Burgermeister, Dick, Garrone, Guggesberg, and Tissot (1963), to have lower initial levels of 5-hydroxy-indolylacetic acid (5HIAA), which reflects overall 5HT metabolism, than those who did not respond to the drug. Also depressed subjects were found by Ashcroft, Crawford, Eccleston, Sharman, MacDougall, Stanton, and Binns (1966) to have a low content of 5HIAA in the cerebrospina fluid, which is a measure of brain 5HT metabolism Low hind-brain 5HT has been reported in depressive suicides by Shaw, Camps, and Eccleston (1967). This was not confirmed by Bourne, Bunney, Colburn Davis, Davis, Shaw, and Coppen (1968), althougle 5HIAA was found to be low.

5HT is formed in vivo from tryptophan by a minor pathway. A quantitatively much more important route of tryptophan metabolism through kynurenine starts with oxidation by liver tryptophan pyrrolase. Increased synthesis of this enzyme was shown by Knox and Auerbach (1955) to result from increased secretion of adrenocortical hormones. Serum cortisol levels have been found by Fullerton, Wenzel, Lohrenz, and Fahs (1968a, b) to be raised in depression, being highest in the most depressed patients and falling during recovery, although Brooksbank and Coppen (1967) consider these changes not fundamentally associated with the illness. Cortisol secretion rates were also reported to be high in depression by Gibbons (1966). There may therefore be a metabolic link between increased adrenocortical activity and abnormal 5HT metabolism in depressionraised plasma cortisol inducing pyrrolase which might directly divert tryptophan from 5HT formation or cause the formation of metabolites which decrease 5HT synthesis. Work by Curzon and Green $(1968,1969)$ and Green and Curzon $(1968,1970)$ on the effects of cortisol and of immobilization stress 
upon rat liver pyrrolase and brain 5HT suggests the possibility of such a mechanism, which has recently been discussed (Curzon, 1969).

Thus it is relevant to determine whether liver tryptophan pyrrolase activity is high in depressed subjects. Direct determination requires liver biopsy which is infrequently justifiable. However, a potential indirect method is available as Altman and Greengard (1966) found that the excretion of kynurenine, after an oral dose of L-tryptophan, is proportional to pyrrolase activity of biopsy material. This method was therefore applied to a group of endogenously depressed and other psychiatric patients. 3-Hydroxykynurenine and 3-hydroxyanthranilic acid, which are formed by the further metabolism of kynurenine (Fig. 1), were also determined.

\section{SUBJECTS}

A consecutive series of patients admitted to the psychiatric beds of the Royal Free Hospital, London, were asked to co-operate with the study and all agreed to be tested. Patients over 60 years old or with significant physical illnesses, including cerebral organic pathology, were excluded from the investigation. The patients were first tested three to four days after admission to allow adjustment to the hospital environment as Fishman, Hamburg, Handlon, Mason, and Sachar (1962) found adrenocortical activity to be sensitive to environmental change.

The patients were placed in one of three diagnostic categories $(1,2$, and 3$)$ with the assistance of the doctors in charge of their treatment. These placements were decided upon before the biochemical results were known. The categories were as follows:

1. DEFINITE ENDOGENOUS DEPRESSION These patients showed evidence of a primary depression with a predominance of typical symptoms such as retardation or agitation, diurnal variation of mood, loss of energy and concentration, self-blame and pessimism, together with anorexia and insomnia. Three of the patients in the female group had had previous bouts of the illness with at least one course of electroconvulsive therapy (ECT).

2. POSSIBLE ENDOGENOUS DEPRESSION In these patients depression was an important part of the clinical presentation, although it appeared to be less fundamental than in patients in group 1 and there were fewer typical symptoms. A major depressive illness was absent from the family history and from the patient's previous history, and there was more often evidence of personality abnormality.

3. ENDOGENOUS DEPRESSION ABSENT These were patients in whom clinically an endogenous depression could be fairly confidently excluded. The most common formulation was that of a vulnerable personality reacting to stresses with anxiety or depression and without signs of major physiological disturbarce.

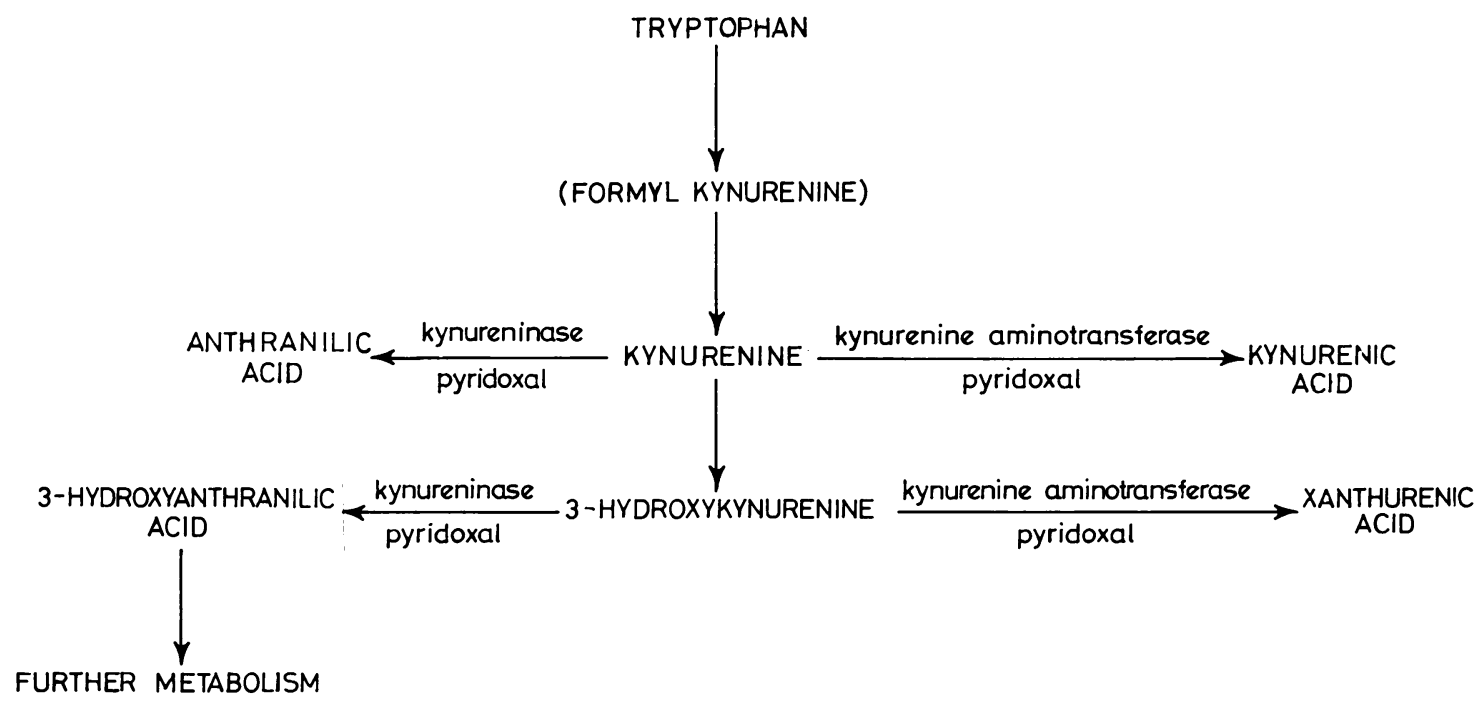

FIG 1. Formation and subsequent metabolism of kynurenine. 


\section{METHODS}

The following procedure was used. At 0800 hours on the first morning of the test urine was voided and discarded. Subsequently all urine passed was collected in 12 hour batches; from 0800 to 2000 and from 2000 to 0800 hours. On the second morning at $\mathbf{0 8 0 0}$ hours a loading dose of $30 \mathrm{mg}$ L-tryptophan $/ \mathrm{kg}$ body weight was given suspended in milk. Urine collection continued in all cases for the next 12 hour period, 0800 to 2000 hours, and for the initial group of patients there was a further fourth 12 hour collection, 2000 to $\mathbf{0 8 0 0}$ hours. Urine was collected into plastic jars containing $5 \mathrm{ml}$. $6 \mathrm{~N} \mathrm{HCl}$. After the volumes had been measured, samples were stored at $-20^{\circ} \mathrm{C}$ until estimations were carried out.

All patients had at least two test periods, the first being done on admission and the second two to three days before discharge. More tests were carried out on four subjects, two (B and I) being discharged and then readmitted, having two tests during each admission. With patient $C$ the second test was carried out in anticipation of discharge as improvement had occurred, but a relapse followed shortly afterwards and the patient remained in hospital for further treatment, a final test being carried out before discharge. It was not possible to withdraw medication during investigations, although it was kept as constant as was compatible with therapeutic requirements. All tests after ECT were done four to 14 days after the final ECT treatment as this itself causes a transient increase of plasma cortisol (Elithorn, Bridges, Hodges, and Jones, 1968).

DETERMINATION OF KYNURENINE A scaled down modification of the method of Tompsett (1959) was used. Five millilitres urine was hydrolysed by $1 \mathrm{ml} .5 \mathrm{~N} \mathrm{HCl}$ in glass-stoppered tubes for one hour in a boiling water bath. The hydrolysate was transferred, with $2 \mathrm{ml}$. water washings, into a $50 \mathrm{ml}$. pear-shaped flask already containing $3 \mathrm{ml} .40 \% \mathrm{NaOH}$, and $5 \mathrm{ml}$. distillate was collected from this into a $5 \mathrm{ml}$. graduated tube in about 10 minutes. Constant heating was obtained using an Electrothermal Heating Mantle with Sunvic control. Bumping was prevented by MS Antifoam A Silicone (Hopkin and Williams, Chadwell Heath, Essex, England) and porous pot. To the distillate $0.2 \mathrm{ml} .5 \mathrm{~N} \mathrm{HCl}$ and $0.1 \mathrm{ml} .0 .5 \%$ sodium nitrite was added and five minutes later $0.1 \mathrm{ml} .2 .5 \%$ ammonium sulphamate. After five minutes $0.1 \mathrm{ml}$. $0.5 \% \mathrm{~N}$-naphthyl ethylenediamine dihydrochloride was added and the purple colour allowed to develop for three hours and read at $540 \mathrm{~m} \mu$ with $1 \mathrm{~cm}$ path in an SP 500 spectrophotometer. Standards of $50 \mu \mathrm{g}$ kynurenine sulphate were carried through the procedure. Blanks gave the same reading as water. Tompsett recommended a control determination with distillation at neutrality to correct for non-specific chromogens. This was done on 11 urines collected in the 12 hour period after tryptophan loading and extinctions equivalent to $2 \cdot 3 \pm 2 \cdot 1 \mu$-mole kynurenine were obtained. This is only a small fraction of the amounts of kynurenine excreted except in a few instances and would not alter the interpretation of results. Therefore the control determination was omitted in subsequent work.
DETERMINATION OF 3-HYDROXYKYNURENINE AND 3-HYDROXYANTHRANILIC ACID A method based upon those of Price, Brown, and Yess (1965) and Healey (1965) was used.

Columns $6 \mathrm{~cm} \times 1 \mathrm{~cm}$ of Dowex $50, \mathrm{H}^{+}$resin were prepared in $30 \mathrm{~cm}$ high glass chromatography columns, washed with $30 \mathrm{ml} .8 \mathrm{~N} \mathrm{HCl}$ followed by $100 \mathrm{ml}$. water, and equilibrated with $0.1 \mathrm{~N} \mathrm{HCl}$. The flow rate was adjusted to 30 to $40 \mathrm{ml}$./hour.

Urine ( $0.5 \%$ of 12 hours) was made to $1 \mathrm{~N} \mathrm{HCl}$ and heated in a boiling water bath for one hour, and then diluted to $0.1 \mathrm{~N} \mathrm{HCl}$ and run through the columns. The columns were then washed with $30 \mathrm{ml} .0 \cdot 1 \mathrm{~N} \mathrm{HCl}$ followed by $40 \mathrm{ml}$. $0.5 \mathrm{~N} \mathrm{HCl}$ and the washings discarded. 3-Hydroxyanthranilic acid was eluted with $30 \mathrm{ml}$. $2 \mathrm{~N} \mathrm{HCl}$ and 3-hydroxykynurenine by $40 \mathrm{ml} .4 \mathrm{~N} \mathrm{HCl}$. 3-Hydroxyanthranilic acid and 3-hydroxykynurenine were determined colorimetrically as Price et al. (1965) against standards treated as urines. Recoveries of 100 to $200 \mu \mathrm{g}$ of standards added to urines was 85 to $115 \%$. Kynurenine is eluted together with 3-hydroxykynurenine and was also determined. Values were in only moderate agreement with those obtained by the distillation method, being in general about $25 \%$ lower except when the distillation method gave $<20 \mu$-mole kynurenine. In these circumstances the colorimetric method gave rather higher values, presumably due to its lower specificity. Occasional urines gave very high kynurenine results with the colorimetric but not the distillation method, and also very high 3-hydroxykynurenine. This indicates interfering drug metabolites (Price et al., 1965) and these results were rejected.

\section{RESULTS}

Results of tests on the initial group of patients, in Table 1, show that the greater part of the kynurenine excreted after a tryptophan load is in the first 12 hour urine collection and that the kynurenine excreted in the second 12 hours is comparable in amount to that excreted in 12 hour periods before the loading dose. Thus kynurenine derived from the load is essentially all excreted within 12 hours and therefore the test period for subsequent patients was reduced from 48 hours to 36 hours. Other workers have also found that tryptophan metabolites derived from loads are excreted within 12 hours of ingestion.

Female and male patients are considered separately. It has been found by Michael, Drummond, Doeden, Anderson, and Good (1964), and by Rapoport and Beisel (1968), but not by Price et al. (1965) that metabolism on the pyrrolase pathway is much more active in females. Table 2 shows kynurenine, 3-hydroxykynurenine, and 3-hydroxyanthranilic acid excretions by female subjects in the 12 hour period after the loading dose of tryptophan was given. It is apparent that in each group of subjects there is a wide range of values and also large differences between values for the same patient at 
TABLE 1

EFFECT OF TRYPTOPHAN LOADING ON URINARY KYNURENINE EXCRETION

\begin{tabular}{|c|c|c|c|}
\hline \multicolumn{4}{|c|}{ Kynurenine excretion in consecutive $12 \mathrm{hr}$ periods ( $\mu$-mole } \\
\hline \multicolumn{2}{|c|}{ Before tryptophan load } & \multicolumn{2}{|c|}{ After tryptophan load } \\
\hline $1 s t 12 \mathrm{hr}$ & 2nd $12 \mathrm{hr}$ & $1 s t 12 \mathrm{hr}$ & 2nd $12 \mathrm{hr}$ \\
\hline & & $\begin{array}{l}22 \cdot 7 \\
66 \cdot 6\end{array}$ & $\begin{array}{l}8.6 \\
7.4\end{array}$ \\
\hline & & 384 & 2.9 \\
\hline $2 \cdot 1$ & $2 \cdot 6$ & $7 \cdot 4$ & 1.9 \\
\hline 10.4 & 6.9 & $24 \cdot 1$ & $10 \cdot 8$ \\
\hline $1 \cdot 3$ & $2 \cdot 3$ & $37 \cdot 0$ & 1.4 \\
\hline $7 \cdot 2$ & $4 \cdot 4$ & $97 \cdot 3$ & 4.8 \\
\hline
\end{tabular}

different times. The highest excretion values found were from patients in group 1 (definite endogenous depression) and group 2 (possible endogenous depression), and with their relatively small numbers of subjects it seemed reasonable to consider these two groups together. Table 2 shows that, whereas kynurenine and 3-hydroxykynurenine excretion by some of the depressive subjects decreased in association with improvement, that by others increased and there was no significant overall difference between the excretions when ill and when improved. The mean kynurenine excretion for group 3 (patients not with endogenous depression) was similar to $27.5 \pm$ 13.3 $\mu$-mole previously reported by Price $e$ t al. (1965) for a control group of female subjects after $2 \mathrm{~g}$ L-tryptophan which is comparable with the $30 \mathrm{mg} / \mathrm{kg}$ given in this study. The mean kynurenine and 3-hydroxykynurenine excretions, but not the 3hydroxyanthranilic acid excretion by groups 1 and 2 combined was significantly greater than the means of group 3. The absence of significant alteration of excretion of 3-hydroxyanthranilic acid, although that of its precursors kynurenine and 3-hydroxykynurenine was increased, is consistent with the finding of greater increase of the excretion of the precursors

TABLE 2

URINARY EXCRETION OF TRYPTOPHAN METABOLITES BY FEMALE SUBJECTS AFTER 30 MG/KG L-TRYPTOPHAN

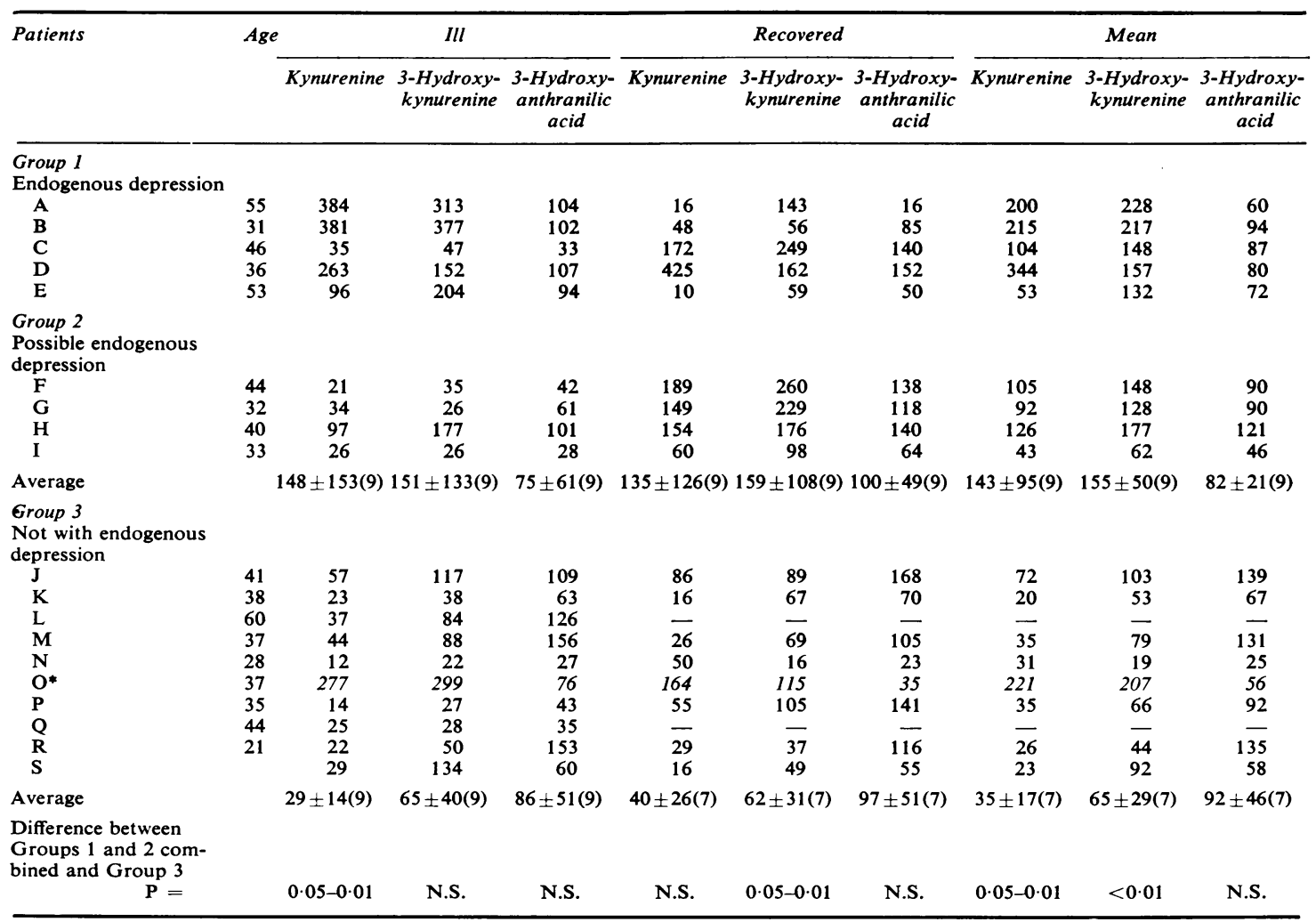

All determinations are in $\mu$-mole. Number of subjects are in parentheses. N.S. $=$ Not significant.

*This subject is described in the text. She was not included in the final statistical calculations, this being justified by the application of Chauvenet's criterion (Faires and Parkes, 1960). 
after hydrocortisone injection (Rose and McGinty, 1968; McGinty and Rose, 1969).

The apparent relationship between the severity of depression and kynurenine excretion after tryptophan load differs for different subjects. Thus patient A was severely depressed and agitated at the time of the first test when $384 \mu$-mole kynurenine was excreted. After a long course of ECT this fell to $14 \mu$-mole at the time of discharge when the patient was much improved. Patient B showed a similar trend, a good response to antidepressant medication being associated with markedly decreased kynurenine excretion. Six weeks later she relapsed and was readmitted. Again kynurenine excretion was high (101 $\mu$-mole) and fell to $60 \mu$-mole after she responded to a course of ECT.

However, other patients did not show the above clear association of a fall of kynurenine excretion with improvement. The two most severely depressed patients were $A$ and $C$ yet in the latter case kynurenine excretion increased from $35 \mu$-mole when ill to $172 \mu$-mole after the first course of ECT when the patient appeared much improved. However, a relapse occurred eight days later and the excretion increased further to $169 \mu$-mole after a second course of ECT just before discharge and eventual return to work. A similar trend is seen for patient $\mathbf{H}$ for whom the level rose after some improvement. The patient then left hospital at her own request, although she agreed she was not fully well. One week later she was readmitted much worse but with a lower kynurenine excretion of $44 \mu$-mole which rose after a successful course of ECT to $99 \mu$-mole.

Patient $F$ presented with a severe phobic illness which had not responded to ECT in the past but was associated with a good deal of depression. She was treated with antidepressant medication, sedative drugs, and deconditioning, and was discharged much improved, being able to travel some distance by underground transport for the first time for many years; but on discharge both kynurenine and 3-hydroxykynurenine excretion were high.

Among the patients without an endogenous depression, kynurenine and 3-hydroxykynurenine excretions by patient $O$ in both tests were much higher than all other members of this group. She had a long history of psychiatric disturbance, her personality was of hysterical type and she was thought to have an associated mixed neurotic illness on this occasion but depression was not an obvious part of the presentation. However, it is interesting that this was the only patient in this group who had received ECT in the past, although without notable improvement at that time.

Fewer men were studied than women (Table 3) and there were only three males in group 1 . All had
TABLE 3

URINARY KYNURENINE EXCRETION BY MALE SUBJECTS AFTER 30 MG/KG L-TRYPTOPHAN

\begin{tabular}{|c|c|c|c|c|}
\hline \multirow[t]{2}{*}{ Patients } & \multirow[t]{2}{*}{ Age } & \multicolumn{3}{|c|}{ Kynurenine $(\mu-$ mole $)$} \\
\hline & & III & Recovered & Mean \\
\hline \multicolumn{5}{|c|}{$\begin{array}{l}\text { Group } 1 \\
\text { Endogenous depression }\end{array}$} \\
\hline Al & 47 & 50 & 44 & 47 \\
\hline B1 & 57 & 28 & 42 & 35 \\
\hline $\mathrm{Cl}$ & 57 & 39 & 16 & 28 \\
\hline \multicolumn{5}{|c|}{$\begin{array}{l}\text { Group } 3 \\
\text { Not with endogenous } \\
\text { depression }\end{array}$} \\
\hline D1 & 22 & 45 & 45 & 45 \\
\hline E1 & 24 & 24 & 57 & 41 \\
\hline F1 & 45 & 36 & 48 & 42 \\
\hline G1 & 45 & 47 & 45 & 46 \\
\hline H1 & 25 & 22 & 105 & 64 \\
\hline I1 & 57 & 16 & 8 & 12 \\
\hline
\end{tabular}

had previous illnesses requiring ECT and were moderately depressed when tested but high kynurenine excretions were not found. One male patient, $\mathrm{H} 1$, who complained of anxiety and was not regarded as significantly depressed, had a high value just before discharge when he had much improved clinically.

Some patients were on phenothiazine drugs, injection of which has been found by Kusch and Heinrich (1963) to cause pyrrolase activity to increase in rats. However Price, Brown, and Peters (1959) reported a lack of effect of chlorpromazine on tryptophan metabolism in human subjects. Patient $B$ showed large changes in kynurenine excretion in three tests $(101,60,384 \mu$-mole), although receiving identical medication ( $400 \mathrm{mg}$ /day chlorpromazine). Other patients were on imipramine or amitriptyline. Mangoni and Paracchi (1965) found these substances to have slight or negligible effects upon pyrrolase activity when injected intraperitoneally into rats at a dosage of 5 to $6 \mathrm{mg} / \mathrm{kg} /$ day. Therefore it seems probable that the results obtained on depressed subjects were not merely due to direct effects of these drugs especially as many patients in group 3 were also taking them.

\section{DISCUSSION}

Previous studies have suggested that tryptophan metabolism on the pyrrolase pathway may be raised in psychoses. Thus Price et al. (1959) and Benassi, Benassi, Allegri, and Ballarin (1961) have found abnormally high increases of tryptophan metabolites after tryptophan load in schizophrenia and depression, although Faurbye and Pind (1964) found schizophrenics to be indistinguishable from normal subjects in a well-controlled study. More recently 
Cazzullo, Mangoni, and Mascherpa (1966) and Rubin (1967) studied tryptophan metabolism in depression and obtained results explicable by increased metabolism on the pyrrolase pathway. Our results also suggest such an association.

Although excretion of kynurenine and 3-hydroxykynurenine by depressive subjects after tryptophan load was high, that of the subsequent metabolite 3-hydroxyanthranilic acid (Fig. 1) was not. This could be due to a limiting effect of kynureninase, the enzyme converting 3-hydroxykynurenine to 3hydroxyanthranilic acid and also kynurenine to anthranilic acid. Kynureninase is a pyridoxal dependent enzyme as is also kynurenine aminotransferase which converts kynurenine and 3-hydroxykynurenine to kynurenic and xanthurenic acids respectively. Thus it is possible that the elevated excretion of kynurenine and 3-hydroxykynurenine may be due to pyridoxal levels being lower in the depressed subjects and thus less able to cope with the tryptophan load. However, while this possibility is not excluded, the finding by Altman and Greengard (1966) of a correlation between kynurenine excretion after tryptophan load and liver pyrrolase activity determined directly on biopsy material indicates that in general high kynurenine excretion is due to high pyrrolase activity.

In the present study great variability of excretion of kynurenine and 3-hydroxykynurenine after tryptophan was found at different times in the same depressive subjects, while excretion by the control group was much less labile. There was no consistent temporal relationship between excretion of metabolites and severity of depressive illness. The observation that some depressed patients appeared to have elevated metabolism on the pyrrolase pathway when recovered suggests that this cannot readily be explained simply as a direct consequence of disturbed mood. It may be a biochemical abnormality present in some subjects who are susceptible to endogenous depression. Evidence that high pyrrolase activity appears to result in low brain 5HT has been obtained in animal work (Curzon and Green, 1968, 1969; Green and Curzon, 1968). Defective brain 5HT synthesis in depressive illness might well be brought about through a number of biochemical variables of which raised tryptophan metabolism on the pyrrolase pathway might be one.

In endogenous depression there is typically a diurnal variation in mood associated with abnormalities of other diurnal rhythms such as those of salivary secretion (Palmai and Blackwell, 1965), urinary electrolytes (Elithorn, Bridges, Lobban, and Tredre, 1966), and plasma cortisol (Bridges and Jones, 1966; Doig, Mummery, Wills, and Elkes, 1966; Knapp, Keane, and Wright, 1967). Normal human subjects have been shown by Rapoport and Beisel (1968) to show a diurnal rhythm of tryptophan metabolism which may be influenced by diurnal variation of cortisol levels affecting pyrrolase synthesis. Therefore, abnormality of the pyrrolase pathway in endogenous depression may be associated with shifts in other rhythms and its significance may be clarified if diurnal changes are studied.

We thank Mrs. D. Kantamaneni for skilled assistance and Sister M. K. Crang of the Royal Free Hospital, who was responsible for nursing the patients in this study and who supervised the urine collections. Dr. Curzon was supported by the Clinical Research Fund of the Ministry of Health and Dr. Bridges by the Royal Free Hospital Endowment Fund.

\section{REFERENCES}

Altman, K., and Greengard, O. (1966). Correlation of kynurenine excretion with liver tryptophan pyrrolase levels in disease and after hydrocortisone induction. $J$. clin. Invest., 45, 1527-1534.

Ashcroft, G. W., Crawford, T. B. B., Eccleston, D., Sharman, D. F., MacDougall, E. J., Stanton, J. B., and Binns, J. K. (1966). 5-Hydroxyindole compounds in the cerebrospinal fluid of patients with psychiatric or neurological diseases. Lancet, ii, 1049-1052.

Benassi, C. A., Benassi, P., Allegri, G., and Ballarin, P. (1961). Tryptophan metabolism in schizophrenic patients. $J$. Neurochem., 7, 264-270.

Bourne, H. R., Bunney, W. E., Colburn Jr., R. W., Davis, J. M., Davis, J. N., Shaw, D. M., and Coppen, A. J. (1968). Noradrenaline, 5-hydroxytryptamine, and 5-hydroxyindoleacetic acid in hindbrains of suicidal patients. Lancet, ii, 805-808.

Bridges, P. K., and Jones, M. T. (1966). The diurnal rhythm of plasma cortisol concentration in depression. Brit. J. Psychiat., 112, 1257-1261.

Brodie, B. B., and Reid, W. D. (1968). Serotonin in brain: functional considerations. Advanc. Pharmacol., 6B, Suppl. pp. 97-113.

Brooksbank, B. W. L., and Coppen, A. (1967). Plasma 11-hydroxycorticosteroids in affective disorders. Brit. J. Psychiat., 113, 395-404.

Burgermeister, J. J., Dick, P., Garrone, G., Guggisberg, H., and Tissot, R. (1963). Urinary excretion of 5-Hydroxyindolacetic acid (5-HIAA) in 150 patients with depressive syndrome and maniacal agitation. Presse méd., 71, 1116-1118.

Cazzullo, C. L., Mangoni, H., and Mascherpa, G. (1966). Tryptophan metabolism in affective psychoses. Brit. J. Psychiat., 112, 157-162.

Coppen, A., Shaw, D. M., Herzberg, B., and Maggs, R. (1967). Tryptophan in the treatment of depression. Lancet, ii, 1178-1180.

Curzon, G. (1969). Tryptophan pyrrolase-a biochemical factor in depressive illness? Brit. J. Psychiat., 115, $1367-1374$.

Curzon, G., and Green, A. R. (1968). Effect of hydrocortisone on rat brain 5-hydroxytryptamine. Life Sci., 7, 657-663.

Curzon, G., and Green, A. R. (1969). Effects of immobilization on rat liver tryptophan pyrrolase and brain 5-hydroxytryptamine metabolism. Brit. J. Pharmacol., 37, 689-697. 
Doig, R. J., Mummery, R. V., Wills, M. R., and Elkes, A. (1966). Plasma cortisol levels in depression. Brit. J. Psychiat., 112, 1263-1267.

Elithorn, A., Bridges, P. K., Lobban, M. C., and Tredre, B. E. (1966). Observations on some diurnal rhythms in depressive illness. Brit. med. J., ii, 1620-1623.

Elithorn, A., Bridges, P. K., Hodges, J. R., and Jones, M. T. (1968). Adrenocortical responsiveness during courses of electro-convulsive therapy. Brit. J. Psychiat., 110, 575-580.

Faires, R. A., and Parks, B. H. (1960). Radioisotope Laboratory Techniques, p. 165, 2nd ed. Newnes: London.

Faurbye, A., and Pind, K. (1964). Investigations on the tryptophane metabolism (via kynurenine) in schizophrenic patients. Acta psychiat. scand., 40, 244-248.

Fishman, J. R., Hamburg, D. A., Handlon, J. H., Mason, J. W., and Sachar, E. (1962). Emotional and adrenal cortical responses to a new experience. Arch. gen. Psychiat., 6, 271-278.

Fullerton, D. T., Wenzel, F. J., Lohrenz, F. N., and Fahs, H. (1968a). Circadian rhythm of adrenal cortical activity in depression. I. A comparison of depressed patients with normal subjects. Arch. gen. Psychiat., 19, 674-681.

Fullerton, D. T., Wenzel, F. J., Lohrenz, F. N., and Fahs, H. (1968b). Circadian rhythm of adrenal cortical activity in depression. II. A comparison of types in depression. Arch. gen. Psychiat., 19, 682-688.

Gibbons, J. L. (1966). The secretion rate of corticosterone in depressive illness. J. psychosomat. Res., 10, 263-266.

Green, A. R., and Curzon, G. (1968). Decrease of 5-hydroxytryptamine in the brain provoked by hydrocortisone and its prevention by Allopurinol. Nature (Lond.), 220, 1095-1097.

Green, A. R., and Curzon, G. (1970). The effect of tryptophan metabolites on brain 5-hydroxytryptamine metabolism. Biochem. pharmacol., 19, 2061-2068.

Healey, A. F. (1965). The effect of pyridoxine on tryptophan metabolism in phenylketonuria. Clin. Sci., 29, 465-473.

Knapp, M. S., Keane, P. M., and Wright, J. G. (1967). Circadian rhythm of plasma 11-hydroxycorticosteroids in depressive illness, congestive heart failure, and Cushing's syndrome. Brit. med. J., 2, 27-30.

Knox, W. E., and Auerbach, V. H. (1955). The hormonal control of tryptophan peroxidase in rat. J. biol. Chem., 214, 307-313.

Kusch, T., and Heinrich, I. (1963). Die Activitätsveränderungen der Leber-tryptophan-pyrrolase und Tyrosin$\alpha$-ketoglutarat-transaminase durch Chlorpromazin und Reserpin unter Berücksichtigung der Functionen der
Nebennieren. Acta biol. med. germ., 10, 554-560.

Mangoni, A., and Paracchi, G. (1965). L'attivita triptofanopirrolasica in ratti trattati con farmaci antidepressivi. Boll. soc. ital. biol. sper., 41, 1552-1554.

McGinty, F., and Rose, D. P. (1969). Influence of androgens upon tryptophan metabolism in man. Life Sci., 8 , 1193-1199.

Michael, A. F., Drummond, K. N., Doeden, D., Anderson, J. A., and Good, R. A. (1964). Tryptophan metabolism in man. J. clin. Invest., 43, 1730-1746.

Palmai, G., and Blackwell, B. (1965). The diurnal pattern of salivary flow in normal and depressed patients. Brit. J. Psychiat., 111, 334-338.

Pare, C. M. B., and Sandler, M. (1959). A clinical and biochemical study of a trial of iproniazid in the treatment of depression. J. Neurol. Neurosurg. Psychiat., 22, 247-251.

Price, J. M., Brown, R. R., and Peters, H. A. (1959). Tryptophan metabolism in porphyria, schizophrenia and a variety of neurological and psychiatric diseases. Neurology (Minneap.), 9, 456-468.

Price, J. M., Brown, R. R., and Yess, N. (1965). Testing the functional capacity of the tryptophan-niacin pathway in man by analysis of urinary metabolites. Adv. metab. Disorder, 2, 159-225.

Rapoport, M. I., and Beisel, W. R. (1968). Circadian periodicity of tryptophan metabolism. J. clin. Invest., 47, 934-939.

Rose, D. P., and McGinty, F. (1968). The influence of adrenocortical hormones and vitamins upon tryptophan metabolism in man. Clin. Sci., 35, 1-9.

Rubin, R. T. (1967). Adrenal cortical activity changes in manic-depressive illness: influence on intermediary metabolism of tryptophan. Arch. gen. Psychiat., 17ळ 671-679.

Schildkraut, J. J. (1965). The catecholamine hypothesis of affective disorders: a review of supporting evidence Amer. J. Psychiat., 122, 509-522.

Shaw, D. M., Camps, F. E., and Eccleston, E. G. (1967) 5-Hydroxytryptamine in the hind-brain of depressive suicides. Brit. J. Psychiat., 113, 1407-1411.

Tompsett, S. L. (1959). The determination in urine of some metabolites of tryptophan-kynurenine, anthranilic acid and 3-hydroxyanthranilic acid-and reference to the presence of $o$-aminophenol in urine. Clin. chim. Acta, 4, 411-419.

Van Praag, H. M., and Leijnse, B. (1963). Die Bedeutung der Monoaminoxydase-hemmung als antidepressives Prinzip. I. Psychopharmacologia (Berl.), 4, 1-14. 